\title{
Erratum
}

\section{Organoselenosilane-Mediated Selective Mild Access to Selenolesters, Selenoanhydrides and Diacyl Diselenides}

Antonella Capperucci, * Alessandro Degl'Innocenti, * Caterina Tiberi Synlett 2011, 2248.

We noticed that in Table 1 , entry $6 \mathrm{R}$ is incorrect. The correct $\mathrm{R}$ group is $i$-Pr and not $n$-Pr. Further, in Scheme 3 the correct formula of product 4 is $\mathrm{Me}_{3} \mathrm{SiSeSiMe}_{3}$ and not $\mathrm{Me}_{3} \mathrm{SiSeSiH}_{2} \mathrm{Me}_{3}$. We apologize for these mistakes and for any inconvenience it may have caused. 